\title{
Behavioral and physiological habituation to an ultrasonic stimulus
}

\author{
DAVID A. THOMAS \\ Department of Biology, Rutgers University, New Brunswick, New Jersey 08903 \\ VAHRAM HAROUTUNIAN \\ Department of Psychology, Princeton University, Princeton, New Jersey 08540 \\ and \\ RONALD J. BARFIELD \\ Department of Biology, Rutgers University, New Brunswick, New Jersey 08903
}

\begin{abstract}
The present report examines the use of a $50-\mathrm{kHz}$ ultrasonic tone in producing both behavioral and physiological responses in rats and assessed the effectiveness of an ear-plugging procedure in blocking these responses. In addition, the habituation of these responses to the tone was investigated. The presentation of the tone resulted in reliable barpress unconditioned suppression and bradycardia, in separate experiments. In both situations, the ear plugs sufficiently attenuated the signal such that neither behavioral nor physiological responses were found.
\end{abstract}

Research in recent years has focused on descriptions of ultrasonic vocalizations produced by rodents in a variety of social situations (Nyby \& Whitney, 1978), but relatively little work has been attempted to assess the cue value of pure ultrasonic tones on behavior and their relative efficacy in learning paradigms. Schleidt (1952) found that ultrasonic stimuli elicit Preyer's reflex and vibrissae movements in wild rodents. However, contrary to the effects commonly found with audible tones, we have not reliably observed any overt responses such as jumping, flinching, or ear twitching to $75-\mathrm{dB}$ tones in the ultrasonic range. It is therefore not clear whether pure tones of moderate loudness in the ultrasonic range can be used as effective stimuli in behavioral studies or whether the degree of sensitivity to, or perception of, ultrasonic stimuli can be documented in nonsocial situations.

The purpose of the present report was to investigate and develop behavioral and physiological paradigms (barpress unconditioned suppression and heart-rate changes) that could index sensitivity to ultrasonic stimuli. An advantage of using these responses over more gross measures, such as flinching or ear twitching, is that with both indexes it is possible to specify the magnitude of the evoked response rather than just the presence or

This research was supported by PHS Grant MH-01562 to Byron A. Campbell, PHS Grant HD-04484 to Ronald J. Barfield, NIMH Postdoctoral Fellowship F32 NS219-78 to Vahram Haroutunian, and NIMH Postdoctoral Fellowship MH 08082 to David A. Thomas. The authors thank Byron Campbell for the generous use of his facilities. Reprint requests should be sent to David A. Thomas, Department of Biology, Rutgers University, Livingston College, New Brunswick, New Jersey 08903. absence of a response. A second goal of this study was to evaluate the effectiveness of a deafening procedure (ear plugging) in attenuating ultrasonic signals. A previous report (Chase, 1979) described an ear-plugging procedure that was effective in attenuating audible tones; however, this reversible deafening procedure was not evaluated with ultrasonic signals, the "penetrance" characteristics of which can be quite different from those of audible tones (Smith, 1979).

\section{EXPERIMENT 1}

Experiment 1 examined unconditioned barpress suppression and subsequent habituation to a $50-\mathrm{kHz}$ tone in the rat.

\section{Method}

Ten Long-Evans female rats, approximately 60 days of age, were individually housed and then reduced to $80 \%$ of their freefeeding weights via food deprivation. All rats were trained in .5 -h daily sessions in a standard Lafayette operant chamber that was placed in a cardboard container with $10.2 \mathrm{~cm}$ of foam rubber on all sides. The operant chamber was isolated in a room adjacent to the room that contained the electromechanical control equipment. Initially, each rat was trained on a continuous reinforcement schedule with 45-mg Noyes food pellet reinforcements. On subsequent days, each animal was gradually shifted to a VR 10 schedule of reinforcement. The range of responses necessary for reinforcement delivery varied from 1 to 17 , and all animals were responding on this schedule by Day 5 of training. An electrostatic ultrasonic speaker was placed in the back of the operant chamber, and a jeweled white cue light was located over the manipulandum. Following 2 weeks of barpress training, the rats were exposed to two presentations of two different stimul in one session. The first and third stimulus presentation was a $50-\mathrm{kHz}$ 75-dB (re $20 \mathrm{microN} / \mathrm{m}^{2}$ ) pulsed (3-pulse/sec) 1-min tone; the second and fourth stimulus presentation was a flashing (10-pulse/sec) 1-min cue light. In both experiments, the tone 
was produced by amplifying a signal from a B \& $\mathbf{K}$ precision No. 3020 sweep/function generator to the electrostatic speaker. Prior to testing, the intensity of the tone was calibrated with a Breul \& Krael .635-cm No. 4135 condenser microphone in line with a single-sweep oscilloscope. The interstimulus interval was $5 \mathrm{~min}$, and the stimulus presentations began $10 \mathrm{~min}$ following the start of the session. On the day prior to testing (following the daily training), five of the animals were anesthetized with ether and a silicon-based ear impression compound (Tru-mold, Scientific Plastics, New York, New York) was injected into the auditory meatus, allowed to dry, and secured in place by suturing the pinna (plugged group). The remaining five rats were anesthetized only (intact group).

\section{Results and Discussion}

The data are of the form $A /(A+B)$, where $A$ is the number of responses during the 1 -min stimulus and $B$ is the number of responses during the minute immediately prior to the stimulus presentation. Ratios of .50 and .0 indicate no suppression and complete suppression, respectively. The ratio scores were subjected to analysis of variance, and Newman-Keuls tests were used for post hoc pairwise comparisons, with alpha set at .05 .

The results for the plugged and the intact groups are displayed in Figure 1. There were significant main effects of condition $[F(1,8)=8.26, p<.025]$, stimulus $[F(1,8)=11.24, p<.025]$, and trials $[F(1,8)=33.6$, $\mathrm{p}<.001]$ and a significant interaction of Stimulus by Trials $[F(1,8)=7.17, p<.05]$. Overall, the plugged group showed less suppression than the intact group, due primarily to the responding during the tone presentations, the light produced more suppression than the tone, and there was more suppression on Trial 1 than on Trial 2, reflecting some habituation to the test stimuli.

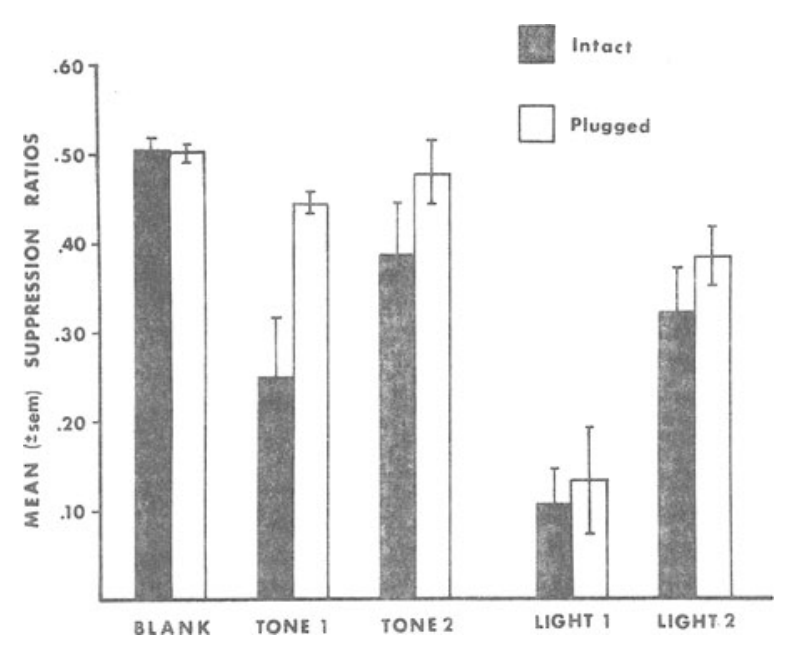

Figure 1. Mean suppression ratios (and standard error) of plugged and intact groups to the light and the ultrasonic stimulus. Although not included in the statistical analysis, the results of a blank trial (no stimulus presentation) that was run immediately prior to the first tone presentation is displayed.
The plugged and the intact groups did not differ on Trial 1 or Trial 2 of the light presentation, nor did they differ on Trial 2 of the tone presentation. Only on Trial 1 of the tone presentation did the intact group exhibit more unconditioned suppression than the plugged group, indicating the effectiveness of the ear plugs in attenuating the ultrasonic tone. Another measure of the effectiveness of the ear plugging can be seen by comparing the responses of each group to the tone vs. the light on each trial. For the intact group, the two stimuli were equally effective on Trial 1 and on Trial 2. This was also the case for the plugged group on Trial 2. On Trial 1, however, the plugged group showed more suppression to the light than to the tone, indicating that the ear plugs sufficiently attenuated the tone and consequently eliminated the barpress unconditioned suppression response. Finally, whereas the intact group habituated to the tone and did not significantly suppress responding on Trial 2, no trial-to-trial differences were apparent in the responses of the plugged group. Both groups showed more suppression on Trial 1 than on Trial 2 during the light presentation, indicating that the lack of change in the response pattern of the plugged group to the tone was not due to some "artifactual" consequence of the ear plugging per se.

\section{EXPERIMENT 2}

A second experiment was undertaken in order to examine the effect of an ultrasonic tone on heart-rate response in rats. This measure was selected primarily because it has been shown to be extremely sensitive to auditory stimuli and is relatively simple to monitor in a controlled environmental setting (Haroutunian \& Campbell, 1981).

\section{Method}

Twenty-five Long-Evans female rats, approximately 40 days old, were maintained as in Experiment 1 . On the day prior to testing, ear plugs were placed in 12 of the animals (plugged group) and the remaining 13 rats were anesthetized only, as in the previous experiment (intact group). Two stainless steel electrodes were inserted subcutaneously in the dorsal and ventral surface of the rat and secured with masking tape, conforming to the procedure specified by Haroutunian and Campbell (1981).

All testing took place in an Industrial Acoustics Company sound- and light-attenuated chamber. Heart rate was recorded by means of a Coulburn Instruments Schmitt trigger interfaced to a Commodore PET microprocessor. The rat was placed in the testing apparatus, and following a 10-min adaptation period, the first of 10 stimulus presentations began. The stimulus was a 5-sec pulsed (3-pulse/sec) $75-\mathrm{dB} 50-\mathrm{kHz}$ tone, and heart rate was recorded during the 5 -sec tone and for the $10 \mathrm{sec}$ following the termination of the stimulus.

\section{Results and Discussion}

Heart-rate data were of the form of beat-per-minute change (BMC) from baseline, and baseline scores were obtained on each trial by averaging the last 10 beats prior to the tone presentation. In the intact group, heart-rate scores for one animal were not available on 
Trials 2 and 10 and for another animal on Trials 8 and 9 due to interference with the signal. The iterative procedure outlined by Myers (1972) was used to estimate the missing values, and consequently, four degrees of freedom were lost from the error term of the overall trials analysis.

There was a change $(p<.01)$ from baseline in the intact group only on Trial 1 (Figure 2). By Trial 2, habituation to the tone had occurred, resulting in little BMC in subsequent trials in the intact group. The onetrial habituation found here was more rapid than that reported for preweanling rats using audible tones (Haroutunian \& Campbell, 1981). It is not clear whether this difference in habituation reflects the frequency of the tone that was used or many of the other parametric differences between these experiments, such as tone duration, age and strain of animals, length of the recording period, and interstimulus interval. It is interesting to note that although the durations of the tone were different, the rates of habituation in both the heart-rate response and barpress unconditioned suppression were identical in these studies. In both cases, an ultrasonic stimulus produced a dramatic decrease in the response being measured on Trial 1 and no change on the subsequent stimulus presentations.

The heart-rate data from the first trial were reanalyzed in blocks of 30 heartbeats in order to further investigate the nature of this heart-rate response (Figure 3). For one animal in the intact group, the data for the blocks analysis were not available. Analysis of variance revealed a significant effect of condition $[F(1,22)=7.28, p<.025]$ and a significant interaction of Condition by Blocks $[F(2,44)=9.46, p<.005]$. Newman-Keuls tests showed that on Block 1 the two groups did not differ but the intact group exhibited a

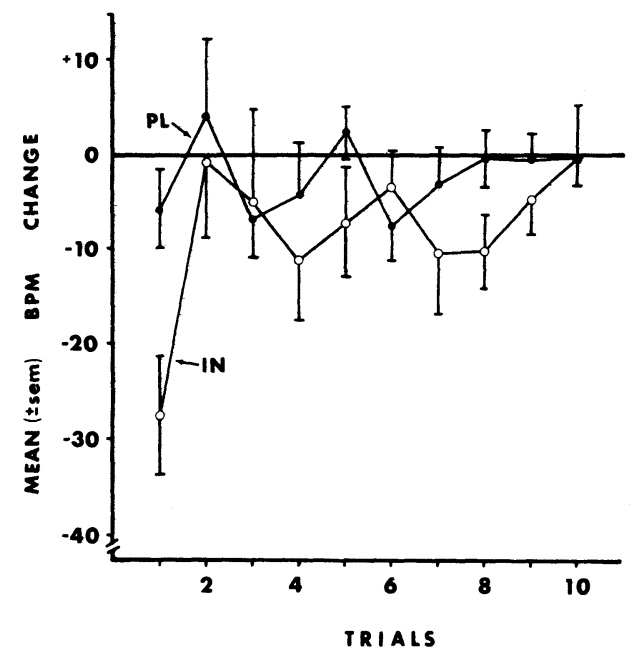

Figure 2. Mean beat-per-minute (BPM) change (and standard error) from the baseline for the plugged (PL) and intact (IN) groups as a function of trials (tone presentations).

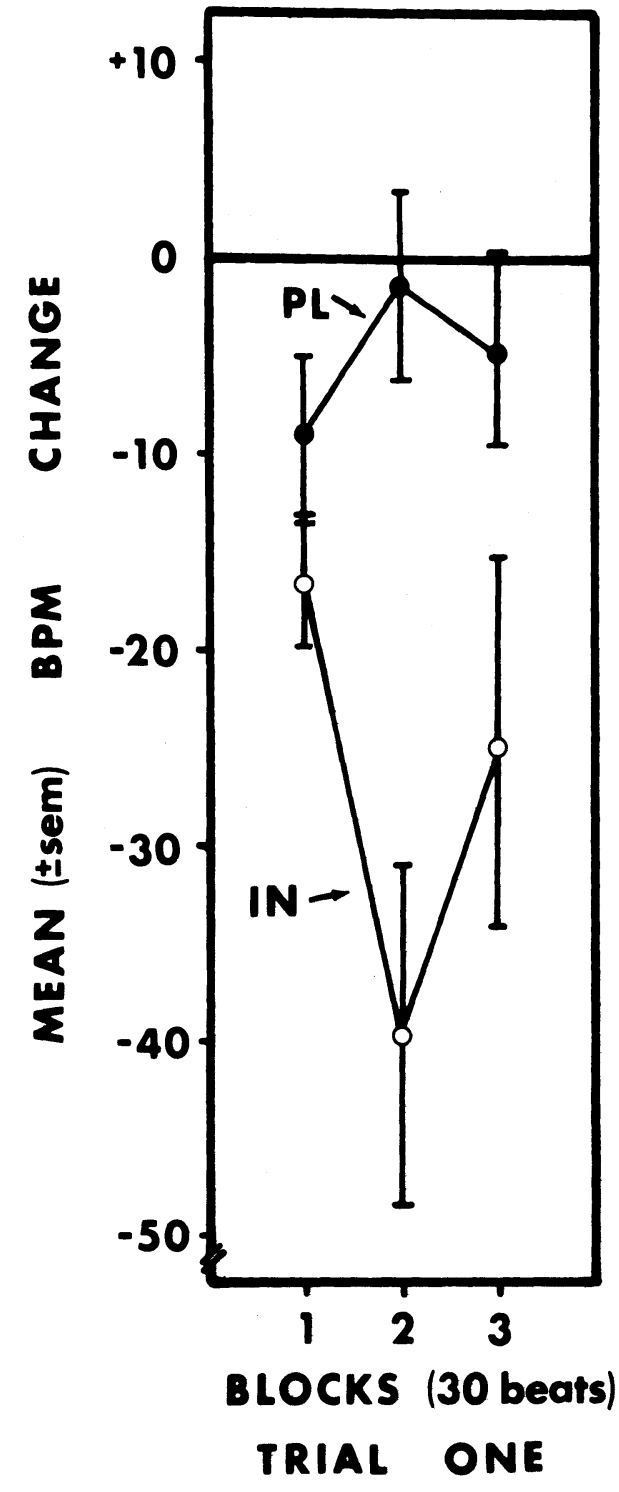

Figure 3. Mean beat-per-minute (BPM) change (and standard error) for the plugged (PL) and intact (IN) groups on Trial 1 as a function of 30 -heartbeat blocks.

significant decrease in heart rate on Block $2(\mathrm{p}<.01)$ and Block $3(\mathrm{p}<.05)$. The bradycardia in the intact group in response to a $50 \mathrm{kHz}$ tone is similar to that found in 19-day-old pups to an audible tone (Haroutunian $\&$ Campbell, 1981). The failure of the plugged group to show a change from baseline, particularly on Trial 1 , is an indication that the ear plugging attenuated the ultrasonic tone below the threshold required to evoke this response.

\section{GENERAL DISCUSSION}

One question not addressed by the present study is the extent of attenuation produced by the ear-plugging technique. 
A previous report (Kerr, Ostapoff, \& Rubel, 1979) showed, using an electrophysiological procedure, that a nearly identical ear-plugging technique in chicks resulted in an approximately $40-\mathrm{dB}$ attenuation across a range of audible frequencies (.125$5.0 \mathrm{kHz}$ ), but the generalizability of these results to attenuation of ultrasounds in rats remains to be demonstrated. Extrapolation from a behaviorally generated audiogram in albino rats, in which a conditioned licking suppression technique was used, indicates that a $50-\mathrm{kHz}$ tone at an intensity of approximately $25 \mathrm{~dB}$ would evoke a response (Kelly \& Masterson, 1977). Given the limitations of generalizability due to differences in strain of animal and nature of response, it is suggested only that the degree of attenuation provided by the present ear-plugging procedure is in the range of $45-50 \mathrm{~dB}$.

The results of the present experiment indicate that a tone of moderate intensity in the ultrasonic range is capable of producing a startle-like response that is subject to habituation, as evidenced by both a behavioral and a physiological measure. In addition, the ear-plugging procedure described above is effective in attenuating the signal to the extent that neither the barpress unconditioned suppression nor the bradycardia is exhibited. Ongoing research in our laboratories indicates that this ear-plugging procedure is equally effective in blocking a conditioned barpress suppression to a $50-\mathrm{kHz}$ ultrasound.

\section{REFERENCES}

Chase, J. Sensory impairment: A useful approach to rodent ultrasound research. American Zoologist, 1979, 19, 529-530. Haroutunian, V., \& Campbell, B. A. Development and habituation of the heart rate orienting response to auditory and visual stimuli in the rat. Journal of Comparative and Physiological Psychology, 1981, 95, 166-174.

Kelly, J. B., \& Masterson, B. Auditory sensitivity of the albino rat. Journal of Comparative and Physiological Psychology, 1977, 91, 930-936.

KerR, L. M., Ostapoff, E. M., \& Rubel, E. W. Influence of acoustic experience on the ontogeny of frequency generalization gradients in the chicken. Journal of Experimental Psychology: Animal Behavioral Processes, 1979, 5, 97-115.

MYERS, J. L. Fundamentals of experimental design. Boston: Allyn \& Bacon, 1972.

NyBY, J., \& Whitney, G. Ultrasonic communication of adult myomorph rodents. Neuroscience and Biobehavioral Reviews, 1978, 2, 1-14.

ScheiLdT, W. Reaktionen auf Töne hoher Frequenz bei Nagern. Naturwissenschaften, 1952, 39, 69-70.

Sмiтh, J. C. Factors affecting transmission of rodent ultrasound in natural environments. American Zoologist, 1979, 19, 432-442.

(Received for publication May 19, 1981.) 